\title{
Propofol versus combined sedation in flexible bronchoscopy: a randomised non-inferiority trial
}

\author{
D. Stolz*\#, G. Kurer*, A. Meyer*, P.N. Chhajed*, E. Pflimlin*, \\ W. Strobel* and M. Tamm*
}

ABSTRACT: Combined sedation with a benzodiazepine and an opiate has been proposed as standard sedation for bronchoscopy. Propofol is a sedative-hypnotic with a rapid onset of action and fast recovery time, but carries the potential risk of respiratory failure.

Consecutive patients $(n=200)$ were randomly allocated to receive either the combination midazolam and hydrocodone or intravenous propofol. The primary end-points were the mean lowest arterial oxygen saturation during bronchoscopy and the readiness-for-discharge score $1 \mathrm{~h}$ after the procedure.

The mean lowest arterial oxygen saturation during bronchoscopy did not differ across treatment groups $(p=0.422)$, and the number of patients recording an arterial oxygen saturation of $\leqslant 90 \%$ on at least one occasion was similar in both groups $(p=0.273)$. The median (interquartile range) readiness-for-discharge score $1 \mathrm{~h}$ after the procedure was significantly higher in the propofol group than in the combined sedation group ( 8 (6-9) versus $7(5-9) ; p=0.035)$. Patients assigned propofol exhibited less tachycardia during bronchoscopy and for $\geqslant 1 \mathrm{~h}$ after the examination. Minor procedural complications were noted in 71 (35.5\%) patients and exhibited a similar incidence in both treatment arms $(p=0.460)$.

Propofol is as effective and safe as combined sedation in patients undergoing flexible bronchoscopy, thus representing an appealing option if timely discharge is a priority.

KEYWORDS: Analgesia, endoscopy, lung, pre-medication, procedure

$\mathbf{T}$ he current guidelines for bronchoscopy recommend offering sedation to all patients undergoing flexible bronchoscopy, except where there are contraindications [1]. The aim of sedation is to achieve good patient tolerance, comfort and cooperation whilst reducing complications of the procedure [2-4]. A recent European survey has shown that $>95 \%$ of centres routinely perform sedated bronchoscopy [5].

Although the ideal sedation for flexible bronchoscopy is not yet defined [1], the combination of a benzodiazepine and an opiate has been shown to improve operating conditions due to its antitussive effect, enhance patient satisfaction and be safe [6] Thus combined sedation using a benzodiazepine and an opiate has been proposed for adoption as standard sedation for patients without contraindications $[7,8]$. In such patients, midazolam is the most commonly used benzodiazepine because of its short duration of action [5]. However, the pharmacokinetic properties of midazolam include a significant variation in individual dose requirements and delayed metabolism, leading to accumulation of the drug in $\sim 6 \%$ of the population $[9,10]$. Both attributes may lead to a prolonged recovery period [11-14]. This has important implications for a busy day-case service, including decreased patient throughput, less efficient use of day-care beds and increased staff-costs.

Propofol (2,6-diisopropylphenol) is a sedativehypnotic frequently used in the induction and maintenance of anaesthesia [15]. Its rapid onset of action and amnesic properties, coupled with smooth and rapid recovery, make propofol an appealing agent for procedural sedation [16, 17]. The significant advantage of a faster recovery time, as compared to other sedatives, has been emphasised in several studies [9, 18-20]. However, to date, there are only limited data evaluating propofol for flexible bronchoscopy and no safety data comparing propofol with combined sedation in this setting. Therefore, a prospective randomised non-inferiority trial was undertaken in order to determine whether
AFFILIATIONS

${ }^{*}$ Clinic of Pulmonary Medicine and Respiratory Cell Research, University Hospital Basel, Basle, Switzerland. \#Harvard School of Public Health, Boston, MA, USA.

CORRESPONDENCE D. Stolz

Clinic of Pulmonary Medicine and Respiratory Cell Research University Hospital Basel Petersgraben 4 4031 Basel Switzerland E-mail: dstolz@uhbs.ch

Received: Nov 282008 Accepted after revision: April 022009 First published online: April 222009 
propofol is as effective and safe as combined sedation with a benzodiazepine and an opiate in patients undergoing flexible bronchoscopy. The primary end-points were the mean lowest arterial oxygen saturation during bronchoscopy and the readiness-for-discharge score $1 \mathrm{~h}$ after the procedure.

\section{METHODS}

\section{Patients}

Consecutive patients $(n=200)$ undergoing elective flexible bronchoscopy were randomly allocated to receive either intravenous propofol or the combination midazolam and hydrocodone as sedative agent. Intubated patients and those with known allergy or intolerance to midazolam, hydrocodone or propofol were not included in the study. Informed consent was obtained from each patient, and the study was approved by the institutional review board, Ethikkommission beider Basel (Basle, Switzerland). The trial was registered with the Current Controlled Trials database (trial number ISRCTN99754241) [21].

\section{Study design}

All patients were assessed by a physician and a member of the nursing team trained in anaesthesiology prior to the procedure, which included gradation of physical status in accordance with the American Society of Anaesthesiologists (ASA) criteria and estimation of the Mallampati score. Bronchoscopy procedures were performed transnasally, with the patients in the semirecumbent position, by a total of four pulmonary fellow physicians under the close supervision of four pulmonary attending physicians. Pulse oximetric results were recorded continuously during the procedure and automated noninvasive blood pressure monitoring was performed every $5 \mathrm{~min}$. Supplemental oxygen was offered at $4 \mathrm{~L} \cdot \mathrm{min}^{-1}$ via a nasal cannula to all patients. In the case of desaturation to $\leqslant 90 \%$, oxygen delivery was increased to $6 \mathrm{~L} \cdot \mathrm{min}^{-1}$ [22]. Nasal anaesthesia was achieved by spraying $10 \%$ lidocaine in the nasopharynx (four times) and oropharynx (twice). Bronchoscopists were advised to instil 3-mL aliquots of $1 \%$ lidocaine over the vocal cords and on to the trachea and both right and left main bronchi. Instilled lidocaine doses were recorded for each patient. All doses of supplemental local anaesthesia required, as judged by the bronchoscopist, were recorded for each patient. No inhaled lidocaine was given prior to the procedure [7].

Patients were randomly assigned to either intravenous propofol or the combination of midazolam and hydrocodone. Every patient's assignment was carried out in the waiting room of the bronchoscopy suite by a research nurse. Randomisation was through arbitrary allocation to one of the two treatment groups based on a computer-generated random list (GraphPad Software, San Diego, CA, USA).

The loading doses of propofol and midazolam were titrated in order to achieve adequate conscious sedation (onset of ptosis for bronchoscopy). Patients assigned the combination of midazolam and hydrocodone received $5 \mathrm{mg}$ intravenous hydrocodone immediately before flexible bronchoscopy [6]. Thereafter, conscious sedation was achieved initially with $2 \mathrm{mg}$ midazolam and followed by further 1-2 mg intravenous midazolam boluses during the procedure at the endoscopist's discretion [6]. The dose of midazolam during the procedure was titrated to maintain conscious sedation, i.e. induce an altered state of consciousness that minimises pain and discomfort but still permits a patient to respond to physical stimulation and maintain an unassisted airway. Patients assigned propofol received an intravenous infusion using an intermittent bolus technique; after an initial $20 \mathrm{mg}$ intravenous propofol, the dose was then carefully titrated. For ASA I and II patients, the steps comprised 10-20 mg intravenous propofol, whereas, for ASA III and IV, exactly $10 \mathrm{mg}$ intravenous propofol was administered based on the clinical response, as previously described [23]. Between each bolus, a pause lasting $\geqslant 20 \mathrm{~s}$ had to be observed. If the effect disappeared during the examination, additional intravenous boluses of $10 \mathrm{mg}$ propofol were given, depending on the clinical effect, in order to maintain the required level of sedation. Signs of pain or discomfort, agitation, persistent cough, and inadequate motor or verbal response to manipulation were considered indicators of insufficient sedation, leading to administration of an additional dose of propofol $(10-20 \mathrm{mg})$ or midazolam (1$2 \mathrm{mg}$ ). The total dose of propofol and midazolam was documented for each patient.

Diagnostic procedures, i.e. brushing, washings, biopsy, bronchoalveolar lavage, and endobronchial and transbronchial biopsy, were performed dependent upon the clinical indication. Haemodynamic parameters, sedation, duration of bronchoscopy, bronchoscopic procedures and complications were noted during the procedure on a form specifically designed for the study. Complications were defined as oxygen desaturation of $\leqslant 90 \%$, need for mandible support, minor and major bleeding, arterial hypotension, need for artificial airway or invasive ventilation, need to abort bronchoscopy, need for intensive care unit (ICU)/intermediate care stay, pneumothorax and death.

At the end of the procedure, bronchoscopists and nursing staff charted their perception of cough during the procedure on a $10-\mathrm{cm}$ visual analogue scale (VAS). Similarly, $2 \mathrm{~h}$ after bronchoscopy, patients were also asked to record their perception of cough related to the procedure on a $10-\mathrm{cm}$ VAS. On this scale, 0 denoted no cough and 10 represented incessant cough. Patients were also asked to record fear and discomfort associated with the procedure on a 10-cm VAS. On this scale, 0 denoted no fear or discomfort and 10 represented the greatest thinkable fear or discomfort. After 1 and $2 \mathrm{~h}$, respectively, patients were asked about their readiness for discharge. On the VAS, 0 denoted no readiness for discharge and 10 represented immediate readiness for discharge. Willingness to undergo repeat flexible bronchoscopy was also documented. Haemodynamic monitoring was performed immediately before, during and shortly after the procedure (after removal of the bronchoscope), and before transfer from the bronchoscopy suite to the recovery room. Moreover, the patient's blood pressure and cardiac frequency were monitored for up to $3 \mathrm{~h}$ after bronchoscopy until discharge.

\section{Data analysis}

Assuming a mean lowest arterial oxygen saturation of $94.8 \%$ with an SD of $2.7 \%$ in the arm treated with the combination of midazolam and hydrocodone [6], a total of 174 patients, 87 in each treatment arm, would be needed to demonstrate that propofol is associated with a mean lowest saturation within $2 \%$ or better of that of the combination of midazolam and hydrocodone, with $90 \%$ power using a one-sided statistical 
test with an $\alpha$ of 0.05 . Assuming a $10 \%$ loss to follow-up, a sample size of 200 patients was projected.

The difference in arterial oxygen saturation change between the randomised groups, taking into account the initial arterial oxygen saturation, was analysed using a general linear model of repeated measures. Differences in dichotomous variables were evaluated using the Chi-squared test or Fisher's exact test, as appropriate. Normally distributed parameters were analysed using an unpaired t-test for equality of means. All other continuously non-normally distributed parameters were evaluated using the nonparametric Mann-Whitney U-test or Kruskal-Wallis test, as appropriate. Correlation analyses between physicians and nursing staff VAS results were performed using Spearman rank correlation.

The Statistical Package for Social Sciences (SSPS, Inc.) version 15 for Windows program (SPSS, Chicago, IL, USA) was used. All test were two-tailed; a p-value of $<0.05$ was considered significant. Results are expressed as mean $\pm \mathrm{SD}$ or median (interquartile range) unless otherwise stated.

\section{RESULTS}

Patient demographics are presented in table 1. There were no significant differences between the two randomised groups in terms of age, presence of comorbid conditions, physical status or Mallampati score.

Table 2 shows the indication, number and distribution of diagnostic procedures per patient, and randomisation group. The main reason for bronchoscopy was pulmonary infection, followed by suspicion of malignancy and interstitial lung disease. Accordingly, the most common diagnostic procedures were bronchoalveolar lavage $(58 \%)$ and bronchial washing $(33 \%)$. Transbronchial needle aspiration, both from the mediastinum and the periphery of the lung, was performed in $30.5 \%$ of cases. The great majority of patients underwent two $(39 \%)$ or three $(35.5 \%)$ diagnostic bronchoscopic procedures. The mean \pm SD midazolam dose required was $8 \pm 3.5 \mathrm{mg}$ and the propofol dose required was $217 \pm 131 \mathrm{mg}$.

\section{Primary end-points}

Mean lowest arterial oxygen saturation during the procedure

The mean lowest arterial oxygen saturation during the procedure was similar across treatment groups $(p=0.422)$ (fig. 1). Correspondingly, there was no significant difference in the arterial oxygen saturation change from baseline through reevaluation between patients randomised to the combination of midazolam and hydrocodone and those randomised to propofol $(p=0.644)$ (fig. 2$)$. The number of patients who recorded a saturation of $\leqslant 90 \%$ on at least one occasion was also similar in both groups (25 midazolam/hydrocodone versus 32 propofol; $p=0.273$ ). The median (interquartile range) maximum oxygen requirement during the procedure did not differ between patients treated with midazolam and hydrocodone (4 (4-8) L) and those treated with propofol (4 (4-8) L; $\mathrm{p}=0.081)$.

\section{Readiness-for-discharge score an hour after the procedure}

The median (interquartile range) readiness-for-discharge score $1 \mathrm{~h}$ after the procedure was 7 [5-9] in patients sedated with the combination of midazolam and hydrocodone and 8 [6-9] in patients sedated with propofol $(p=0.035)$. An hour after the procedure, a readiness-for-discharge score of $\geqslant 6$ was noted in 59 patients treated with the combination midazolam and hydrocodone and in 75 patients treated with propofol $(p=0.003)$. A total of 17 patients were unable to answer any question at the re-evaluation $1 \mathrm{~h}$ after the procedure (16 midazolam/hydrocodone versus 1 propofol; $\mathrm{p}<0.001$ ). Eight patients were still drowsy and unable to speak $2 \mathrm{~h}$ after the procedure (seven midazolam/hydrocodone versus one propofol; $\mathrm{p}=0.030$ ).

\section{Secondary end-points}

The haemodynamic findings before, during and after bronchoscopy are shown in table 3.

As compared to combined sedation with midazolam and hydrocodone, patients assigned propofol exhibited less tachycardia during bronchoscopy, and this difference in cardiac frequency was significant for $\geqslant 1 \mathrm{~h}$ after the procedure. Systolic blood pressure was higher at the end of bronchoscopy in patients sedated with the combination midazolam and hydrocodone $(p=0.002)$.

Procedural complications were noted in 71 (35.5\%) patients and exhibited a similar incidence in both treatment arms $(p=0.460)$ (fig. 3). The most common complications were the need for chin support $(n=68 ; 34 \%)$ and an arterial oxygen saturation of $\leqslant 90 \%(n=57 ; 28.5 \%)$. A nasopharyngeal tube was

\begin{tabular}{|c|c|c|c|}
\hline \multirow[t]{2}{*}{ TABLE 1} & $\begin{array}{l}\text { aracteristics } \\
\text { dergoing flex }\end{array}$ & $\begin{array}{l}200 \text { consec } \\
\text { bronchoss }\end{array}$ & \multirow[b]{2}{*}{ p-value } \\
\hline & \multicolumn{2}{|l|}{ hydrocodone } & \\
\hline Subjects $\mathbf{n}$ & 100 & 100 & \\
\hline Age yrs & $61.6(21-87)$ & $61.0(23-89)$ & 0.895 \\
\hline Male sex & $65(65)$ & $62(62)$ & 0.659 \\
\hline Height $\mathbf{c m}$ & $170.6 \pm 8.6$ & $171.3 \pm 9.5$ & 0.853 \\
\hline Weight kg & $76.0 \pm 17.1$ & $73.9 \pm 16.4$ & 0.323 \\
\hline Current smoker & $28(28)$ & $30(30)$ & 0.876 \\
\hline Ex-smoker & $42(42)$ & $41(41)$ & 0.886 \\
\hline Smoking history pack-yrs & $31.1 \pm 33.2$ & $27.1 \pm 27.1$ & 0.396 \\
\hline \multicolumn{4}{|l|}{ Comorbid conditions } \\
\hline Malignancy & $35(35)$ & $33(33)$ & 0.765 \\
\hline COPD & $25(25)$ & $25(25)$ & 1.000 \\
\hline Immunosuppression & $25(25)$ & $16(16)$ & 0.115 \\
\hline Cardiopathy & $20(20)$ & $13(13)$ & 0.182 \\
\hline Renal failure & $4(4)$ & $5(5)$ & 0.733 \\
\hline Stroke & $3(3)$ & $3(3)$ & 1.000 \\
\hline Alcoholism & $2(2)$ & $3(3)$ & 0.651 \\
\hline Platelets $10^{9} \mathrm{~g} \cdot \mathrm{L}^{-1}$ & $308 \pm 169$ & $295 \pm 144$ & 0.641 \\
\hline ASA physical status & $3(2-3)$ & $3(2-3)$ & 0.777 \\
\hline Mallampati score & $2(2-3)$ & $2(2-3)$ & 0.355 \\
\hline \multicolumn{4}{|c|}{$\begin{array}{l}\text { Data are presented as mean } \pm \mathrm{SD} \text {, mean (range) for age, median (interquartile } \\
\text { range) for ASA physical status and Mallampati score, or } n(\%) \text {, unless otherwise } \\
\text { indicated. COPD: chronic obstructive pulmonary disease; ASA: American } \\
\text { Society of Anesthesiologists. }\end{array}$} \\
\hline
\end{tabular}




\begin{tabular}{|c|c|c|c|c|c|}
\hline \multirow[t]{2}{*}{ TABLE 2} & \multicolumn{5}{|c|}{$\begin{array}{l}\text { Indication for examination, number and } \\
\text { distribution of diagnostic procedures per patient, } \\
\text { and randomisation group in } 200 \text { patients } \\
\text { undergoing flexible bronchoscopy }\end{array}$} \\
\hline & & $\begin{array}{l}\text { Midazolam/ } \\
\text { hydrocodone }\end{array}$ & Propofol & Total & $\mathrm{p}$-value \\
\hline \multirow{2}{*}{\multicolumn{2}{|c|}{$\begin{array}{l}\text { Subjects n } \\
\text { Indication }\end{array}$}} & 100 & 100 & 200 & \\
\hline & & & & & \\
\hline \multicolumn{2}{|l|}{ Infection } & $38(38)$ & $28(28)$ & $66(33)$ & 0.133 \\
\hline \multicolumn{2}{|c|}{ Suspicion of malignancy } & $31(31)$ & $31(31)$ & $62(31)$ & 1.000 \\
\hline \multicolumn{2}{|c|}{ Interstitial lung disease } & $13(13)$ & $12(12)$ & 25 (12.5) & 0.831 \\
\hline \multicolumn{2}{|c|}{ Pre/post-interventional } & $6(6)$ & $7(7)$ & $13(6.5)$ & 0.774 \\
\hline \multicolumn{2}{|c|}{ Haemoptysis } & $3(3)$ & $5(5)$ & $8(4)$ & 0.721 \\
\hline \multicolumn{2}{|c|}{ Chronic cough } & $2(2)$ & $2(2)$ & $4(2)$ & 1.000 \\
\hline \multicolumn{2}{|c|}{ Bronchial toilette } & $1(1)$ & $2(2)$ & $3(1.5)$ & 1.000 \\
\hline \multicolumn{2}{|c|}{ Miscellaneous } & $6(6)$ & $13(13)$ & 19 (9.5) & 0.099 \\
\hline \multicolumn{6}{|c|}{ Diagnostic procedures } \\
\hline \multicolumn{2}{|c|}{ Bronchial washings } & $28(28)$ & $38(38)$ & $66(33)$ & 0.133 \\
\hline \multicolumn{2}{|c|}{ Bronchial brushing } & $18(18)$ & $13(13)$ & $31(15.5)$ & 0.329 \\
\hline \multicolumn{2}{|c|}{ Endobronchial biopsy } & $17(17)$ & $18(18)$ & $35(17.5)$ & 0.852 \\
\hline \multicolumn{2}{|c|}{ Transbronchial biopsy } & $24(24)$ & $22(22)$ & $46(23)$ & 0.737 \\
\hline \multicolumn{2}{|c|}{ Bronchoalveolar lavage } & $62(62)$ & $54(54)$ & $116(58)$ & 0.252 \\
\hline \multicolumn{2}{|c|}{ TBNA mediastinum } & $27(27)$ & $19(19)$ & $46(23)$ & 0.179 \\
\hline \multicolumn{2}{|c|}{ TBNA periphery } & $8(8)$ & $7(7)$ & $15(7.5)$ & 0.788 \\
\hline \multicolumn{2}{|l|}{ EBUS } & $3(3)$ & $5(5)$ & $8(4)$ & 0.470 \\
\hline \multicolumn{6}{|c|}{ Procedures per patient } \\
\hline \multicolumn{2}{|c|}{ Inspection alone } & $4(4)$ & $4(4)$ & $8(4)$ & 1.000 \\
\hline \multicolumn{2}{|l|}{ Two } & $36(36)$ & $42(42)$ & 78 (39) & 0.469 \\
\hline \multicolumn{2}{|l|}{ Three } & $37(37)$ & $34(34)$ & $71(35.5)$ & 0.383 \\
\hline \multicolumn{2}{|l|}{ Four } & $17(17)$ & $15(15)$ & $32(16)$ & 0.705 \\
\hline \multicolumn{2}{|l|}{ Five } & $4(4)$ & $4(4)$ & $8(4)$ & 1.000 \\
\hline \multicolumn{2}{|l|}{ Six } & $2(2)$ & $1(1)$ & $3(1.5)$ & 1.000 \\
\hline
\end{tabular}

Data are presented as $n(\%)$, unless otherwise indicated. TBNA: transbronchial needle aspiration; EBUS: endobronchial ultrasonography

required in three cases; one patient was transferred to the ICU. There were no deaths.

The median (interquartile range) duration of the procedure was similar in patients receiving midazolam and hydrocodone (17 (10-24) $\mathrm{min})$ and in those receiving propofol (17 (928) min; $p=0.941$ ) (table 4). There was also no difference in the required dose of lidocaine in the two randomised groups $(p=0.926)$. Cough scores, as judged by the bronchoscopists and nursing staff, did not differ between patients randomised to combined sedation and propofol. Conversely, cough scores, as judged by patients themselves, were significantly lower in the group treated with combined sedation than with propofol. There was no difference in the discomfort related to the procedure across treatment groups $(p=0.162)$.

Arterial carbon dioxide tension $\left(\mathrm{Pa}_{\mathrm{a}} \mathrm{CO}_{2}\right)$ was assessed in 42 $(84 \%)$ out of the 50 patients with chronic obstructive pulmonary disease before the procedure. In these patients, the mean $\pm \mathrm{SD}$ forced expiratory volume in $1 \mathrm{~s}$ was $1.54 \pm 0.67 \mathrm{~L}$ and $56 \pm 19 \%$ of the predicted value. The mean $\mathrm{Pa}_{1} \mathrm{CO}_{2}$ was $40.2 \pm 4.9 \mathrm{mmHg}$. Hypercapnic status, as defined by a $\mathrm{Pa}_{1} \mathrm{CO}_{2}$ of $\geqslant 45 \mathrm{mmHg}$ on arterial blood gas analysis, was evidenced in

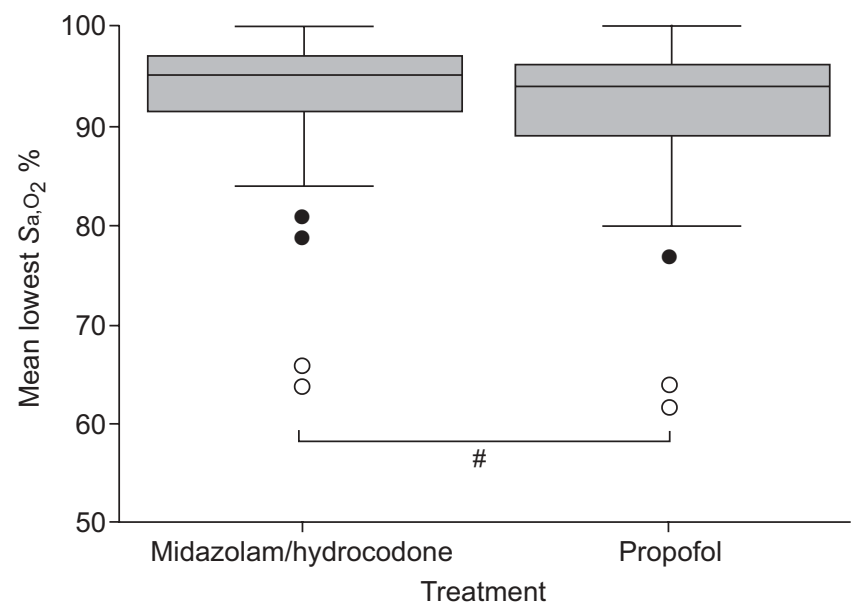

FIGURE 1. Mean lowest arterial oxygen saturation $\left(\mathrm{Sa}_{1} \mathrm{O}_{2}\right)$ during bronchoscopy in the two patient groups. Boxes represent median and interquartile range; whiskers represent range. $\bullet$ : outliers; $\bigcirc$ : extreme outliers. ${ }^{\#}: p=0.422$

five cases. In hypercapnic patients, chin support was required in three cases, and arterial oxygen saturation of $\leqslant 90 \%$ was documented in two cases during the procedure. These figures did not differ significantly from those observed in normocapnic patients $(\mathrm{p}=0.716$ and $\mathrm{p}=0.891$, respectively).

\section{DISCUSSION}

The present study has demonstrated that the mean lowest arterial oxygen saturation and number of procedural complications are similar in patients receiving the combination midazolam and hydrocodone and those receiving propofol for sedation during flexible bronchoscopy. Herein, operating conditions, as assessed by duration of the procedure or need for supplemental lidocaine, were also comparable. Therefore, propofol is a valid alternative to combined sedation with a benzodiazepine and an opiate. The use of propofol was associated with a significantly higher readiness-for-discharge score $1 \mathrm{~h}$ after the examination and a lower proportion of persistent sedation $2 \mathrm{~h}$ after bronchoscopy, whereas the use of combined sedation was associated with lower cough scores as assessed by patients. Hence, both drugs regimens have peculiar sedating characteristics and the choice of one over the other might rely on the preferences of the patient and bronchoscopist, as well as on infrastructural circumstances, e.g. expected time to discharge.

To the present authors' knowledge, this is the first randomised controlled non-inferiority trial comparing propofol with the combination of a short-acting benzodiazepine and an opiate as a sedative agent during flexible bronchoscopy. The combination of a short-acting benzodiazepine and an opiate has been shown to improve operating conditions due to its antitussive effects and to improve patient satisfaction. Thus it has been suggested that combined sedation be adopted as standard sedation for patients without contraindications, particularly if diagnostic bronchoscopic procedures, e.g. transbronchial biopsy, are performed $[6,7]$. Former studies on propofol were performed utilising a benzodiazepine alone or a long-acting benzodiazepine [24-26]. RANDELL [26] showed a significantly lower respiratory frequency in patients receiving the combination 


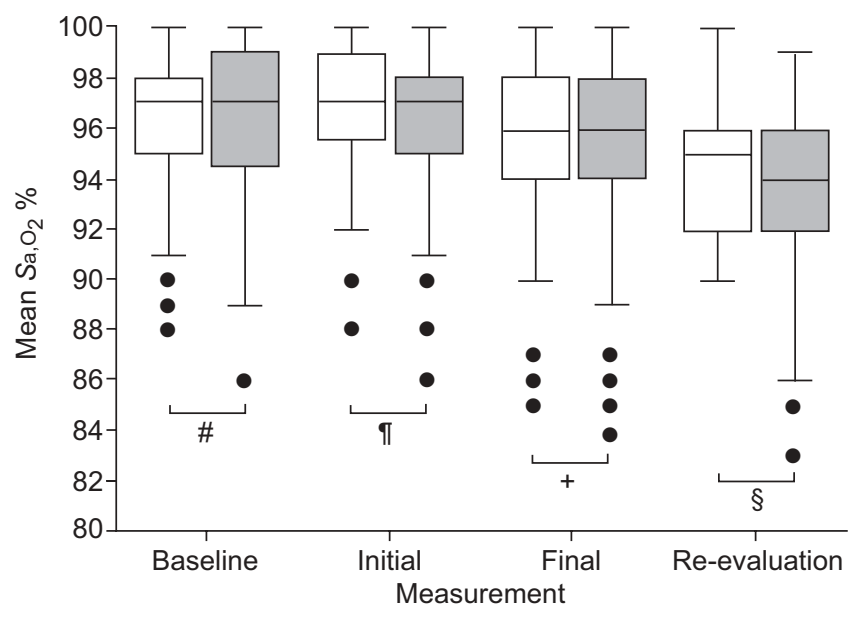

FIGURE 2. Mean arterial oxygen saturation $\left(\mathrm{Sa}_{\mathrm{a}} \mathrm{O}_{2}\right)$ with midazolam/hydrocodone ( $\square$ ) and propofol ( $\square$ ) at baseline, at the beginning of the procedure (Initial), at the end of the procedure (Final) and on re-evaluation after $1 \mathrm{~h}$. Boxes represent median and interquartile range; whiskers represent range. $\bullet$ : outliers. There was no significant difference in the $\mathrm{Sa}_{1} \mathrm{O}_{2}$ change with time across groups $(p=0.644)$. \#: $p=0.625 ;$ " : $p=0.436 ;{ }^{+}: p=0.653 ;{ }^{\varsigma}: p=0.481$.

diazepam and fentanyl as compared to propofol alone. However, midazolam has replaced diazepam in most centres due to its shorter duration of action compared to diazepam, and is now by far the most common sedative used during bronchoscopy $[1,5]$.

CRAWFORD et al. [25] compared sedation for flexible bronchoscopy provided by incremental doses of midazolam alone with that provided by a computer-controlled infusion of propofol. Operator and patient acceptability, anxiolysis, and the effect on systolic arterial pressure did not differ between the groups. Conversely, arterial oxygen saturation during the procedure fell more in those who received propofol than in those who received midazolam ( $83 \%$ in the propofol group and $86 \%$ in the midazolam group). It is well known that both propofol and midazolam may produce respiratory depression [25, 27]. Contrary to the current British Thoracic Society recommendations, oxygen supplementation was not routinely provided in that study. Supplemental oxygen is routinely given to all patients undergoing flexible bronchoscopy at most institutions $[1,28]$. The present randomised trial showed that, if supplemental oxygen is routinely provided during bronchoscopy, propofol does not cause a greater fall in arterial oxygen saturation than does the combination of midazolam and hydrocodone.

KESTIN et al. [24] examined the cardiovascular stability and rate of recovery in patients receiving propofol infusions with or without alfentanil for rigid oesophagoscopy and/or bronchoscopy. All patients received a neuromuscular blocker during induction of anaesthesia and were intubated for the endoscopic procedure. The authors found no difference in haemodynamic parameters, recovery time or adverse events in the two groups, but patients receiving propofol combined with alfentanil required a mean lower dose of propofol during the procedure. Since all patients were intubated for the examination, this study does not permit any inferences about safety in non-intubated patients undergoing routine flexible

\begin{tabular}{|c|c|c|c|c|}
\hline \multirow{2}{*}{$\begin{array}{l}\text { TABLE } 3 \\
\text { Measuremer }\end{array}$} & \multicolumn{4}{|c|}{$\begin{array}{l}\text { Haemodynamic findings before, during and after } \\
\text { bronchoscopy in patients randomised to } \\
\text { sedation with the combination of midazolam and } \\
\text { hydrocodone and propofol }\end{array}$} \\
\hline & & $\begin{array}{l}\text { Midazolam/ } \\
\text { hydrocodone }\end{array}$ & Propofol & p-value \\
\hline Subjects $\mathrm{n}$ & & 100 & 100 & \\
\hline \multicolumn{5}{|l|}{ Baseline } \\
\hline Systolic BF & $\mathrm{nmHg}$ & $138 \pm 22$ & $134 \pm 24$ & 0.105 \\
\hline Diastolic B & $\mathrm{mmHg}$ & $79 \pm 17$ & $80 \pm 15$ & 0.713 \\
\hline Cardiac fre & uency beats $\cdot \mathrm{min}^{-1}$ & $83 \pm 14$ & $83 \pm 16$ & 0.816 \\
\hline \multicolumn{5}{|l|}{ Initial } \\
\hline Systolic BP & $\mathrm{nmHg}$ & $133 \pm 26$ & $128 \pm 23$ & 0.060 \\
\hline Diastolic B & $\mathrm{mmHg}$ & $80 \pm 16$ & $78 \pm 16$ & 0.192 \\
\hline Cardiac fre & uency beats $\cdot \mathrm{min}^{-1}$ & $88 \pm 15$ & $83 \pm 15$ & 0.040 \\
\hline \multicolumn{5}{|l|}{ Final } \\
\hline Systolic BF & $\mathrm{nmHg}$ & $135 \pm 24$ & $125 \pm 26$ & 0.002 \\
\hline Diastolic B & $\mathrm{mmHg}$ & $78 \pm 15$ & $73 \pm 23$ & 0.098 \\
\hline Cardiac fre & uency beats $\cdot \mathrm{min}^{-1}$ & $91 \pm 16$ & $87 \pm 15$ & 0.013 \\
\hline \multicolumn{5}{|c|}{ Re-evaluation after $1 \mathrm{~h}$} \\
\hline Systolic BF & $\mathrm{nmHg}$ & $122 \pm 20$ & $122 \pm 22$ & 0.832 \\
\hline Diastolic B & $\mathrm{mmHg}$ & $71 \pm 14$ & $71 \pm 17$ & 0.993 \\
\hline Cardiac fre & uency beats $\cdot \mathrm{min}^{-1}$ & $90 \pm 14$ & $85 \pm 17$ & 0.040 \\
\hline \multicolumn{5}{|c|}{ Re-evaluation after $2 \mathrm{~h}$} \\
\hline Systolic BF & $\mathrm{nmHg}$ & $131 \pm 20$ & $129 \pm 18$ & 0.906 \\
\hline Diastolic B & $\mathrm{mmHg}$ & $78 \pm 11$ & $76 \pm 11$ & 0.288 \\
\hline Cardiac fre & uency beats $\cdot \mathrm{min}^{-1}$ & $84 \pm 13$ & $83 \pm 14$ & 0.469 \\
\hline
\end{tabular}

Data are presented as mean $\pm S D$, unless otherwise indicated. BP: blood pressure. Values in bold show statistical significance.

bronchoscopy. Nevertheless, it is tempting to speculate that the combination of propofol and hydrocodone could reduce the total propofol dose required during flexible bronchoscopy.

Although both drugs performed equally well with regard to safety in the present study, we found significant differences between the two groups in post-operational VAS readiness-fordischarge score and the number of patients showing signs of persistent sedation $2 \mathrm{~h}$ after the procedure. These findings are in accordance with previous data suggesting that midazolam causes significant impairment of memory and motor reactions $60 \mathrm{~min}$ after the end of the procedure [9, 25]. Accordingly, central nervous system impairment may persist for $\geqslant 3.5 \mathrm{~h}$ after antagonism of midazolam sedation with flumazenil, although patients may have a subjective feeling of alertness, which might have dangerous consequences [29].

Considering the mean doses required in the present study, sedation with propofol was five times more expensive than sedation with the combination of midazolam and hydrocodone (mean cost $15.66 \pm 9.46$ versus $2.92 \pm 0.18$ Euros, respectively). Nevertheless, the costs related to sedative medication represent only a small percentage of the overall cost of bronchoscopy. Although figures may vary markedly across countries, continuous peri-interventional monitoring generates up to a third of the procedure cost in Switzerland. Prolonged sedation may prevent discharge, thus disrupting a tight schedule and 


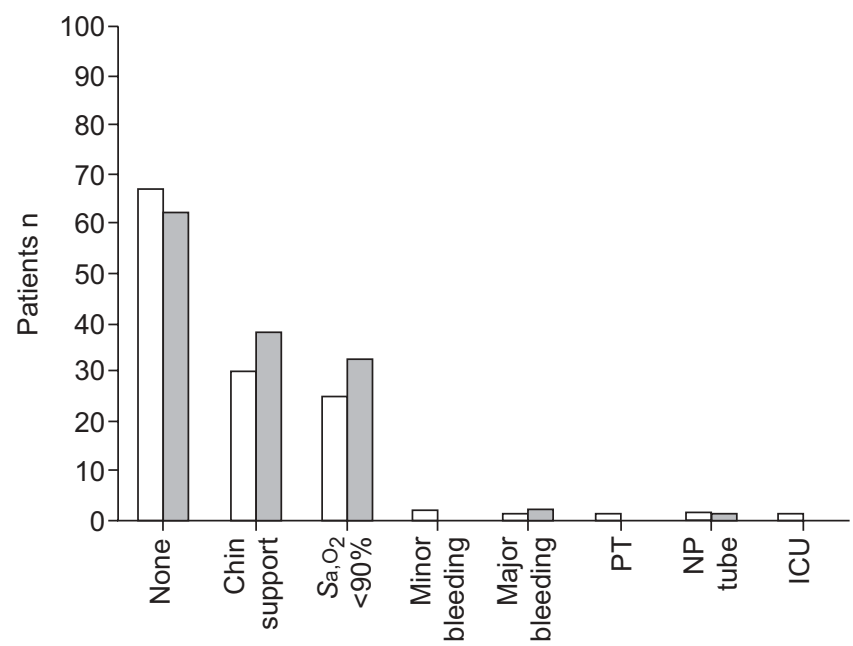

Complication

FIGURE 3. Complications of bronchoscopy in patients assigned the combination midazolam and hydrocodone $(\square ; n=100)$ and propofol ( $\square ; n=100) . S a, \mathrm{O}_{2}$ arterial oxygen saturation; PT: pneumothorax; NP: nasopharyngeal; ICU: intensive care unit.

increasing procedural costs. Therefore, having proved that propofol is as effective and safe as standard combined sedation with a benzodiazepine and an opiate, the present data suggest that propofol might be an appealing option if timely discharge is a priority for either the patient or medical staff.

Interestingly, cough scores, as judged by the patients themselves, were significantly lower in the group treated with combined sedation than that treated with propofol. In contrast, cough scores, as judged by the bronchoscopists and nursing staff, did not differ between the randomised groups. We hypothesise that these findings can be explained by the amnesic effect of midazolam. According to several previous studies, the wake-up time for combined sedation with an opiate and a benzodiazepine is 35-60 $\mathrm{min}$ and discharge time 75-120 min after the procedure [30-32]. Alternatively, propofol might have a shorter or less potent effect on the cough reflex than the combination of midazolam and hydrocodone [33, 34].

The incidence of adverse events in the present study was similar to that described in previous reports $[9,35]$. It is worth noting that it is now appreciated that oxygen desaturation during invasive endoscopic procedures is a common phenomenon, both with $[9,35]$ and without oxygen supplementation [31]. This observation emphasises the importance of standard pulse oximetry and oxygen supplementation during flexible bronchoscopy, as stated in the British Thoracic Society guidelines [1]. Additionally, particular care should be taken in patients at higher risk of carbon dioxide retention during bronchoscopy [1]. Pre-operative arterial blood gas assessment is usually required in such patients. Although the present data do not demonstrate an obviously increased risk of propofol sedation in hypercapnic patients, monitoring of transcutaneous carbon dioxide may be useful in avoiding the complications related to any kind of sedation in these highrisk patients [36].

\begin{tabular}{|c|c|c|c|c|}
\hline \multirow[t]{2}{*}{ TABLE 4} & \multicolumn{4}{|c|}{$\begin{array}{l}\text { Outcome parameters in patients randomised to } \\
\text { sedation with the combination of midazolam and } \\
\text { hydrocodone and propofol }\end{array}$} \\
\hline & & $\begin{array}{l}\text { Midazolam/ } \\
\text { hydrocodone }\end{array}$ & Propofol & p-value \\
\hline Subjects $n$ & & 100 & 100 & \\
\hline Duration of $t$ & e procedure min & $17(10-24)$ & $17(9-28)$ & 0.941 \\
\hline Lidocaine dc & $\mathrm{mg}$ & $132 \pm 40$ & $136 \pm 44$ & 0.926 \\
\hline \multicolumn{5}{|c|}{ Cough score VAS } \\
\hline Physician & & $4(2-6)$ & $5(2-7)$ & 0.781 \\
\hline Nurse & & $4(2-7)$ & $5(3-7)$ & 0.489 \\
\hline Patient & & $0(0-3)$ & $2(0-6)$ & $<0.001$ \\
\hline Discomfort s & ore (patient) VAS & $0(0-0)$ & $0(0-0)$ & 0.162 \\
\hline \multicolumn{5}{|l|}{ Fear VAS } \\
\hline Today's brc & choscopy & $0(0-2)$ & $0(0-3)$ & 0.151 \\
\hline Future bror & hoscopy & $0(0-0)$ & $0(0-0)$ & $<0.007$ \\
\hline \multicolumn{5}{|c|}{ Readiness for discharge VAS } \\
\hline After $1 \mathrm{~h}$ & & $7(5-9)$ & $8(6-9)$ & 0.035 \\
\hline After $2 \mathrm{~h}$ & & $9(7-10)$ & $9(7-10)$ & 0.131 \\
\hline
\end{tabular}

The present study has a few limitations. We used a standardised VAS score, a subjective tool, for assessing readiness for discharge following bronchoscopy. Taking into account that the short halflife of propofol is well described [9], we believe that it was fair to apply a clinical tool for appraising discharge suitability. Thus we refrained from performing formal measurements of motor and verbal function. Further, this was not a blinded study and the specific macroscopic characteristics of propofol facilitate its identification. In this context, concerns regarding potential drops in arterial oxygen saturation might have resulted in a less-thanoptimal dose in those patients allocated to the propofol arm. This might be the reason why patients treated with propofol showed higher cough scores (judged by the patients themselves). Another factor to consider is that the nursing staff of Basle University Hospital (Basle, Switzerland) have considerable expertise in sedation with propofol for all endoscopic procedures, including upper and lower intestinal tract endoscopic procedures. Therefore, and similarly to many other European countries, there is no requirement for an anaesthesiologist to be present during sedation in our institution. Hence, caution might be needed when introducing this sedative regimen in other institutions with less experienced nursing staff. The strengths of the present study are the large number of patients included, the diversity of bronchoscopic procedures and the original randomised non-inferiority design.

In conclusion, our data suggest that propofol is as effective and safe as combined sedation in patients undergoing flexible bronchoscopy. Therefore, propofol represents a valid alternative to combined sedation with a benzodiazepine and an opiate, particularly if timely discharge is a priority.

\section{CLINICAL TRIALS}

This trial is registered with the Current Controlled Trials database (trial number ISRCTN99754241). 


\section{SUPPORT STATEMENT}

This study was supported by the Clinic of Pulmonary Medicine and Respiratory Cell Research (University Hospital Basel, Basle, Switzerland).

\section{STATEMENT OF INTEREST}

None declared.

\section{REFERENCES}

1 British Thoracic Society Bronchoscopy Guidelines Committee, a Subcommittee of Standards of Care Committee of British Thoracic Society, British Thoracic Society guidelines on diagnostic flexible bronchoscopy. Thorax 2001; 56: Suppl. 1, i1-i21.

2 Gonzalez R, De-La-Rosa-Ramirez I, Maldonado-Hernandez A, et al. Should patients undergoing a bronchoscopy be sedated? Acta Anaesthesiol Scand 2003; 47: 411-415.

3 Putinati S, Ballerin L, Corbetta L, et al. Patient satisfaction with conscious sedation for bronchoscopy. Chest 1999; 115: 1437-1440.

4 Matot I, Kramer MR. Sedation in outpatient bronchoscopy. Respir Med 2000; 94: 1145-1153.

5 Pickles J, Jeffrey M, Datta A, et al. Is preparation for bronchoscopy optimal? Eur Respir J 2003; 22: 203-206.

6 Stolz D, Chhajed PN, Leuppi JD, et al. Cough suppression during flexible bronchoscopy using combined sedation with midazolam and hydrocodone: a randomised, double blind, placebo controlled trial. Thorax 2004; 59: 773-776.

7 Stolz D, Chhajed PN, Leuppi J, et al. Nebulized lidocaine for flexible bronchoscopy: a randomized, double-blind, placebocontrolled trial. Chest 2005; 128: 1756-1760.

8 Stolz D, Pollak V, Chhajed PN, et al. A randomized, placebocontrolled trial of bronchodilators for bronchoscopy in patients with COPD. Chest 2007; 131: 765-772.

9 Clarkson K, Power CK, O'Connell F, et al. A comparative evaluation of propofol and midazolam as sedative agents in fiberoptic bronchoscopy. Chest 1993; 104: 1029-1031.

10 Shelley MP, Wilson P, Norman J. Sedation for fibreoptic bronchoscopy. Thorax 1989; 44: 769-775.

11 Williams TJ, Bowie PE. Midazolam sedation to produce complete amnesia for bronchoscopy: 2 years' experience at a district general hospital. Respir Med 1999; 93: 361-365.

12 Williams TJ, Nicoulet I, Coleman E, et al. Safety and patient acceptability of intravenous midazolam for fibre optic bronchoscopy. Respir Med 1994; 88: 305-307.

13 Chudnofsky CR, Weber JE, Stoyanoff PJ, et al. A combination of midazolam and ketamine for procedural sedation and analgesia in adult emergency department patients. Acad Emerg Med 2000; 7: 228-235.

14 Bailey PL, Pace NL, Ashburn MA, et al. Frequent hypoxemia and apnea after sedation with midazolam and fentanyl. Anesthesiology 1990; 73: 826-830.

15 Bryson HM, Fulton BR, Faulds D. Propofol. An update of its use in anaesthesia and conscious sedation. Drugs 1995; 50: 513-559.

16 Zed PJ, Abu-Laban RB, Chan WW, et al. Efficacy, safety and patient satisfaction of propofol for procedural sedation and analgesia in the emergency department: a prospective study. CJEM 2007; 9: 421-427.

17 Berkenbosch JW, Graff GR, Stark JM, et al. Use of a remifentanilpropofol mixture for pediatric flexible fiberoptic bronchoscopy sedation. Paediatr Anaesth 2004; 14: 941-946.
18 Hohl CM, Nosyk B, Sadatsafavi M, et al. A cost-effectiveness analysis of propofol versus midazolam for procedural sedation in the emergency department. Acad Emerg Med 2008; 15: 32-39.

19 Rodrigo MR, Jonsson E. Conscious sedation with propofol. Br Dent J 1989; 166: 75-80.

20 Gasparovic S, Rustemovic N, Opacic M, et al. Clinical analysis of propofol deep sedation for 1,104 patients undergoing gastrointestinal endoscopic procedures: a three year prospective study. World J Gastroenterol 2006; 12: 327-330.

21 Current Controlled Trials. International Standard Randomised Controlled Trial Number Register. www.controlled-trials.com/ isrctn/trial/ Date last updated: February 14, 2008. Date last accessed: February 14, 2008.

22 Chhajed PN, Glanville AR. Management of hypoxemia during flexible bronchoscopy. Clin Chest Med 2003; 24: 511-516.

23 Heuss LT, Schnieper P, Drewe J, et al. Safety of propofol for conscious sedation during endoscopic procedures in high-risk patients - a prospective, controlled study. Am J Gastroenterol 2003 98: 1751-1757.

24 Kestin IG, Chapman JM, Coates MB. Alfentanil used to supplement propofol infusions for oesophagoscopy and bronchoscopy. Anaesthesia 1989; 44: 994-996.

25 Crawford M, Pollock J, Anderson K, et al. Comparison of midazolam with propofol for sedation in outpatient bronchoscopy. Br J Anaesth 1993; 70: 419-422.

26 Randell T. Sedation for bronchofiberoscopy: comparison between propofol infusion and intravenous boluses of fentanyl and diazepam. Acta Anaesthesiol Scand 1992; 36: 221-225.

27 Bell GD, Reeve PA, Moshiri M, et al. Intravenous midazolam: a study of the degree of oxygen desaturation occurring during upper gastrointestinal endoscopy. Br J Clin Pharmacol 1987; 23 703-708

28 Smyth CM, Stead RJ. Survey of flexible fibreoptic bronchoscopy in the United Kingdom. Eur Respir I 2002; 19: 458-463.

29 Andrews PJ, Wright DJ, Lamont MC. Flumazenil in the outpatient A study following midazolam as sedation for upper gastrointestinal endoscopy. Anaesthesia 1990; 45: 445-448.

30 Greig JH, Cooper SM, Kasimbazi HJ, et al. Sedation for fibre optic bronchoscopy. Respir Med 1995; 89: 53-56.

31 Webb AR, Doherty JF, Chester MR, et al. Sedation for fibreoptic bronchoscopy: comparison of alfentanil with papaveretum and diazepam. Respir Med 1989; 83: 213-217.

32 Bright E, Roseveare C, Dalgleish D, et al. Patient-controlled sedation for colonoscopy: a randomized trial comparing patientcontrolled administration of propofol and alfentanil with physician-administered midazolam and pethidine. Endoscopy 2003; 35: 683-687.

33 Guglielminotti J, Rackelboom T, Tesniere A, et al. Assessment of the cough reflex after propofol anaesthesia for colonoscopy. $\mathrm{Br}$ Anaesth 2005; 95: 406-409.

34 Eddy NB, Halbach H, Braenden OJ. Synthetic substances with morphine-like effect. Clinical experience: potency, side-effects addiction liability. Bull World Health Organ 1957; 17: 569-863.

35 Schnapp LM, Cohen NH. Pulse oximetry. Uses and abuses. Chest 1990; 98: 1244-1250.

36 Evans EN, Ganeshalingam K, Ebden P. Changes in oxygen saturation and transcutaneous carbon dioxide and oxygen levels in patients undergoing fibreoptic bronchoscopy. Respir Med 1998, 92: 739-742. 